\title{
UTILIZING ONLINE MEDIA TO RAISE PUBLIC AWARENESS ABOUT PUBLIC HEALTH
}

\author{
Siswanta \\ Communication Science - Slamet Riyadi University Surakarta \\ e-mail: siswanta@live.com
}

\begin{abstract}
The purpose of this research is to analyze the digital media as a primary health information source websites and its effects on individuals both tangible and intangible. This research may be can help to explain the phenomena of the credibility of online media. Most importantly, the research tries to give contributions to the online media as message senders and individual as receivers or users.

Based on a case study, this research studies the credibility of online media as a source of health information. This research has two aims, first to investigate some depth of understanding of how the internet's users seeking health information via online. Second, to identify the framework which has been theoretically explored and empirically demonstrated to describe the process of communication activities in cyberspace with the digital media as a health information source to fullfill their information needs. Semistructured and online interviews with relevant online digital media users as well as important informans, are truly conducted.

Results showed that cognitive factors are more significant used to describe several communication activities for seeking health information in cyber space. In this case, information about the health care problem by nettizen perceived as a form of a very urgent needs for the nettizen having health problems. Credibility is the criteria into consideration for nettizen to access online media in order to meet the needs of health information quickly and accurately. Online media that explicitly affiliated with professional organizations such as Ikatan Dokter Indonesia (IDI) by nettizen are perceived as a source of health information that has a high level of credibility.
\end{abstract}

Keywords: information, online media, public health

\section{INTRODUCTION}

Starting at the beginning of the 1990s, it has been exploring the web-based information society in third world countries, including Indonesia. Even in the education, internet media began to be known as a source of new information, which is more credible than other mass media that are still conventional. It is undeniable that the online media since the late 1990s has changed society's view for the credibility of traditional media organizations (http://www.peoplepress.org). Internet becomes a source of new information, online media will always be updated at any time when needed and even they are able to keep all the information that is readily accessible to online media visitors who are concerned at anytime and anywhere by the network access either using communication media such as wired or wireless LANs Wi-Fi.

One interesting topics discussed in online media is information about health, including types of diseases as well as prevention and treatment solutions are generally written by competent doctors, paramedics or organization in the field of health. Not a bit of a health article writer on online media are those who do not have 
specific experience in the field of journalism professionally. Solely they rely on their practical experience that they are poor in their journalistic ability online media in the form of blogs, websites maintained by individuals, social networking sites such as twitter, Facebook and Paths and etc, as well as mainstream online media like portal Detikhealth.com, Klikdokter.com, Tanyasaja.com and many more sites similar sites. The lastmentioned sites could be a potentially major source of information needed by people who need health information either credible or relatively more accessible by anyone. In other words, the question arises whether the presence of online media has really changed the pattern of distribution of health information. In the context of news as the products, they are actually better able to provide internet user community satisfaction. On this issue, we are also trying to analyze the issue of research using the uses and gratification model or method of communication as a tool of analysis. We also realize that the theoretical approach contains many weaknesses and it is not fully met among others several inherent theory assumptions. For example, the assumptions of the availability of the diversity mass media as an alternative condition to the use of media as a source of information. In the early presence of these theories are new to the print media community and electronic media such as; radio, television and film, and even then the number and variety of them are very limited yet another aspect of the literacy rate is still low as a constraint actuality Katz's theory. However, at the time of telematics technology has remarkable developed as it is today, we need to rethink and reexamine the actualization of the usage of gratification theory as enrichment research. There are more and more research studies are focused on the aspects of the satisfaction of using mass media as a source of information; there are more open opportunity to answer the theoretical problem of the of uses and gratification theory. The more competitive climate of the mass media so by the presence of online media where these conditions will create competition among mass media to seize their market share in the middle of the overflow of information media, especially online media in quantity and variety, is almost unlimited. It is realized that the online media still exist and get a high credible rating visitors in the users' point of views.

Tuchman (1978) arguing that whether the news potential or not to be good news, all depends on the capacity of each network news online media company that has the ability to capture information and the ability to present the news. Moreover, about this argument, as which have been published in the year of 1978, we believe that the internet is able to fill a gap of news network in the modern life that make the news far more complete than the previous one before digital media is present in our midst.

This paper will analyze the phenomenon of online media that focus on the credibility of online media to meet the needs of public health information for internet users, as well as to answer the theoretical problem of renewal of uses and gratification models of communications. This theory grew and developed in the 1940 s and 1950s, in which the growth of the mass media types and varieties are not as fast as today. At that time, the mass media is identical to the conventional 
media, while contemporary media -based telematics technology have not known yet.

Unlike the conventional media, the internet search and information processing is now much easier and faster even with a very high degree of accuracy among other media used the internet to search for health information. Search health information generally made through search engines such as Google, AltaVista, Lycos and so on. This method is taken if they do not have sufficient preference about the sources of health-related information. The utilization search engine will immediately bring many alternatives on the intended site. However, hundreds or even thousands of resources offered by the search engines actually make confuse users of the Internet itself, among others, because of the credibility of sources of health information (web site) those have not certainty known. The use of search engines requires our website visitors who are good at sorting between websites that contain garbage like web sites that contain pornography using the name of health terms resembling and high credibility websites cleverly.

Differently to website visitors who familiar with online media have been focusing on the content of the field of health information. Internets visitors are no longer necessary use search engines, but will directly go to the intended online media site. In fact, nowadays the website has become the primary choice as a source of easy and inexpensive health information. As the data shown by the Pew Internet \& American Live Project (2002), $80 \%$ of Americans seek online health information by accessing the Internet. To serve the needs of the search for health information on the internet, there are approximately 17,000 health sites in internet. For example if we use the Google search engine and keywords, then type the word 'cancer', it will appear around 12.7 million articles, this example occurs when trying to access Google on October 28, 2002 (Susannah; 2011). In order to eliminate much information, we need to be very clever to create a category of internet information is based on certain aspects such as government institutions, medical and science journals have been published or traditional mass media industry also expanded in the online media.

Government agencies such as the Ministry of Health is a pioneer who started the socialization of health issues through online media on the internet, followed by several educational institutions such as the Faculty of Medicine, UI, IDI, and so on . With a capacity of more financial support including human resources, government institutions play an important role as a pioneer of health information dissemination via previously website published information through conventional media. Among the Web portal owned by the government relatively always updated, among others, department of health go id, id co FKUI, IDI dot com and etc.

Web portals managed by government institutions usually also provide features of Journal of science and health. It is one of the many types of medical resource which most frequently accessed by internet users. Wehrwein (1998) says, the News England Journal of Medicare has been a topic of the greatest news for health information in the United States and decorates the preaching room there. Likewise, the health scientific journal of American Medical Association Journal (JAMA dot com), The Lancet, science, and Nature has also played a significant role as a source of health information that is authoritative and 
credible due to standard material content notification and selectivity articles based on the strict editorial review system which they apply.

Responding to the development of online media today, almost all the conventional mass media, including the mass media engaged in health information have developed its coverage to enter the online media. Printed media like Kompas, Tempo, Detik and others also the media publish their digital versions as complement the content of the information with health articles, or better known as ehealth. The comprehensiveness of health information is also supported by the presence of a variety of specialized mass media published in the digital version as Detikhealth.com, Klikdokter.com, Onklinic.com and etc. E-health becomes a major alternative website for nettizen as stated David Owen (1998).

Two important characteristics that are not found in traditional media are the nature of the unlimited and the interactive nature of the internet users. First, the unlimited space/content is unique properties owned by media online. Online media is not familiar with the term publishing a daily, monthly or weekly. Online media will update its news contents whenever necessary. Even on a regular basis, they will update their news average for every 1 hour and even then if there is no breaking news that is considered very important. Cyberspace perform the function of journalism is continuously deeper and sharper (Stepp, 2000). An editor of The Lancet, John Mc Connell (2000) says, many visitors have been interested in accessing the BBC website. The Lancet due BBC news website has made a hyperlink to medical journals. Mc Connell underlined that tendency to put important information on general news sites or portals like Yahoo is guiding people to access a special website to obtain more detailed information. Finally, mass media get real-time information, and sources of the latest information. But in the digital era, as now people quickly and practically will access the website to meet those needs, instead go to the library as the previous options. The website can be regarded as a huge library that is in the grip of internet visitors. The second uniqueness of the characteristics of online media is interactivity. Hariss (1995) says that the computerization and digital media can educate humans. One time, passive media can be interactive media, computerization. The media is not only gives color to the visitors, but also interact with them. The interactive nature of the media can serve as a provider of information, the right resources with visitor information via a digital media network of internet users themselves.

Peter Aldhous (2001) Nature news editor, argues, the typical advantages of the internet is a very specific sophistication required of each individual. For example, some of the contents were very interesting from Nature online is about the search for a job. If you find a job by reading advertising (ads) take a long time, but as you can choose the right conditions as you wish then just look for that, it needs short period of time.

Associated with health information more specifically Doherty Jude (2000) executive producer Washingtonpost.dot.com emphasize the interactive aspects as where Washington post cooperate with MSNBC video clip on the menu to add articles Washington post when it was required. Eve- Marie Lacroix (2000) chairman of the division of public 
services at the National Library of science also said that MEDLINEPlus adds drawings every kind of illustration on different aspects of cancer and other diseases that the public has a better understanding of the information.

The pattern of people behavior in his capacity as a communicant in the process of mass communication draws attention to using two approaches: Uses and Gratification theory models of communication. The theory developed by Elihu Katz in 1959 provides answers to the issue of what was done the public of the existence of the mass media in an effort to meet their information needs. The strict competition in the mass media, there are some worries about the presence of online media become the main competitor of conventional media and it suppose that the presence of online media will gradually replace the print media. That concern is quite reasonable considering the early period of online media presence and online media format content is not much different from the format and content of the print media. To distinguish between two things as if only on a technical problem because online media access at the time were as if only conventional media outlets displayed in the virtual world of the internet.

On line media gradually began to find the format and content in accordance with its own characteristics, a distinctive characteristic of online journalism that is not owned by the conventional media. However, with the advent of mobile devices and ubiquitous Internet access, users have been enabled to produce content themselves. This gave rise to a new form of media companies: the platform operators, who aggregate, manage, and distribute user-generated content (Hess; 2014). Of course the media content online could not be separated from the digital media format which tend to be more easily accessed via the device of PC computers, laptops, tablets and smart phones. The mass media are indogen which allow a user to access it without the limitations of time and place. The Aksesebilitas encourage the netizen to take advantage of online media as a reference to reducing the uncertainty about any information related to health problems. Uncertainty reduction theory reiterates that the search patterns of information following the principles of High levels of uncertainty cause increases in informationseeking behavior. U.s. uncertainty levels decline, information-seeking behavior decreases (Griffin; 2006).

But according to Katz, a major problem in mass communication research is not focus on how the media to change attitudes and behavior of the audience, but focus on how the mass media can meet the needs of personal and social audiences ( Effendi ; 1993). Therefore, this theory assumes the existence of active audience factor that deliberately used the media to achieve specific objectives that led to the satisfaction of using the media of their choice.

\section{METHODS}

As qualitative research is static, since the beginning of the research focus has been directed at the development of the concept - the concept of exposure online media, investigation in searching information in online media, and the satisfaction level of online media are used as the selection focuses. Although the research focus has been directed by the characteristics of qualitative research; flexible and open process and inductive 
analysis, formulation of research problems remain the main reference in the data gathering and analysis of research results. Therefore the questions (guided interview) as one tool of collecting primary data will be used to answer the question of how and why these things happen that basically leads to a form of presentation completing the process of causal relationship. In this case, the causal relationship between the concepts studied were digital media exposure, patterns of information search on the web portal and online media satisfaction usage (Sutopo; 2006).

Primary data were obtained from informants from society in which consist of individuals who usually need and access e-health websites. Because the studies were conducted in Cyberspace, the population is not bound by geographic location but the population comes from website, including social networking or blog or sites users and blogs who actively in accessing e-health information. The population in this study is intended some nettizens (Nettizen is a term that is common language used among Internet users refers to the community of Internet users). Sample or snapshot of data, which is meant here is the user (online media visitors), which acts as an informant and seemed will be able and cooperative to provide information about the data research needed. The number of informants was selected based on criterionbased selection techniques (Sutopo; 2006). Selected informants is the website visitors (users) who are not blind about telematics technology, have easy access to the Internet anytime and unrestricted by the place and others aspects even relatively interacted online in a public space, and those who have easy access to the conventional mass media in order to meet the information field health.

The research setting is in the realm of cyberspace. Understanding the location empirically is not defined as a geographical location, but rather in the perception of the intended location that is media interaction and communication in cyberspace in the form of a website that became the foundation of the Internet users or Nettizen to communicate and interact in order to meet the information needs about health sectors. The coverage of the terminology areas of research carried out on three news websites often visited by many internet users are addressed such as: http://www.detikhealth.com and http://www.klikdokter.com and http://www.tanyasaja.com.

The data collection begins with observation to obtain preliminary data, and then find key informants to capture data sources with the criteria as already stimulated among other website visitors who have accessed actively the e-health whether through mainstream online media, blogs and social networking. Data collected from depth interviews with informants is done through the engine messengers like Yahoo Messenger, Windows Messenger, Skype, and Facebook Messenger and even through private message in social networking sites such as twitter, Facebook as well as in offline depth interviews.

Furthermore, referring to the synthesis of a definitive understanding of the data compiled by Afufuddin, data analysis is the process of organizing and sorting data into patterns, categories, and unit basic description, the researcher can find the theme and then it can be formulated the working hypotheses as it is based by the data (Afifuddin; 2009). In general, data 
analysis in qualitative research performed throughout the study process. Effort analysis has been conducted in several months and running smoothly with the memo, diagrams oration and searching the relationship between the core and subcategories, as well as a narrative description of the overall analysis (Corbin; 2003).

Furthermore, the validity level of the collected data needs to be tested through triangulation techniques. This step must be done, so that the danger of reliable data validity level which will be presented and analyzed when draw overall general conclusion of each case studied meet the best results. Therefore make conclusions in qualitative research is not just present the results of the analysis fragmentary, but rather present something that can be an important part of a larger construction, which leads to efforts to build a new thesis or further build the new theory (Muhadjir; 2002).

Referring to the process of interactive analysis of Huberman and friends reported that in each stage of the data collection process is completed in accordance with the information needed then immediately do the analysis in three interlink cycles i.e. data display, condensing data and images for verification purposes conclusions. In short, data analysis refers to Huberman: Analysis of three concurrent flow activities: (1) the data condensation, (2) the display data, and (3) conclusion drawing / verification (Huberman; 2014).

\section{EMPIRICAL FINDING AND DISCUSSION}

The impact of technological development telematics is not just affect on the technical development of the mass communication media but also impact on the development of online journalism with a distinctive character. One similar characteristic of the most prominent from various online media is the speed nature of the information flow to get audiences and the time and place access that is no longer becomes an obstacle, once again it goes with the personal computers or smart phones connected for 24 hours.

Behinds the advantages of online media is becoming a typical characteristic of the contemporary media, it does not mean the development of online media without a drawback. Barriers to the development of online media can be technical and non-technical barriers such as the Internet network constraints that have not reached the whole community. While non-technical barriers is more directed at the cultural aspects such as the literacy rate of telematics technology, so the adoption of telematics technology can only work with the assumption that people are not blind to digital communications technology. Literacy contemporary media technology becomes absolutely necessary and indeed can meet the assumptions of low in financial costs and minimize in time. Hence, we understand why the culture of online media usage is still limited to people with post-secondary education level or people who have low telematics technological literacy. Even for those who are already literate in telematics technology, mostly to access digital media from public facilities such as accessing digital media with Internet access facilities offices, schools and public spaces are already covered hotspot areas as facilities for the public. As an illustration, in Indonesia the majority of people $(40 \%)$ access the Internet from the office, $31 \%$ 
access the internet from home, $24 \%$ access the internet from the cafe and 5\% access the Internet from other places than those already mentioned previously (Noegroho; 2010).

To give an idea about the aspects certain aspects characterized online media, a characteristic may not be owned by the conventional mass media, researchers took three mainstream online media as samples which present health information; Klikdokter.com, Detikhealth.com and Tanyasaja.com.

Related to the content of online mass media, this study focus on the content related to the health problems of the main stream of online media and the researcher only analyzed three online media as the samples; Detikhealth.com, Tanyasaja.com and Klikdokter.com. Detikhealth.com and Tanyasaja.com is a digital media and mainstream media affiliationKsecond dot com where this media digital media in Indonesia is the first time that actually has the characteristics of online media. Meanwhile, the media online Klikdokter.com is an online media focused on the health sector, the mainstream online media which is financially supported by the profit organizations and public institutions affiliations such as the health department, the Indonesian Doctors Association (IDI), Faculty of Medicine, UI, and so on.

Tanyasaja.com is one fairly large online media having news formats tend to use form or question and answer dialogue among its visitors. This web portal is quite popular among nettizen proven in the past two years had been able to get in hundreds or thousands of active visitors (Jauhari; 2010). Unfortunately, online media affiliated with the detik.com news portal are not very long in their existence, only a little over two years old. Not enough data to explain why just ask dot com disappeared from circulation in cyberspace. There is some speculative analysis on the closure of the portal Tanyasaja.com, among others purportedly already too many similar products on the detik.com itself. Another possibility is Tanyasaja.com is not able to compete with other similar online media such as website Kaskus, somersault and Yahoo! Answer Indonesia. As we all know the format and content of the three types of online media are not much different.

In Indonesia, the mass media were come and out into the realm of the internet is commonplace. As noted earlier, there are currently more than five hundred online media in Indonesia that have gone collaps. Tanyasaja.com closure of online media dot com strengthens the evidence that financial factors are not the main causes of online media bankruptcy in Indonesia. To the phenomenon that occurs in Tanyasaja.com website, a variety of responses emerged from among visitors to the site. Most users expressed disappointment with some of the comments. Zikey Nova e.g. leave comments on blogs that reveal Nurudin.jauhari.net seems that we do not need to regret the closure Tanyasaja.com, because, according to Nova (27 November 2010 at 15:35 pm) the possibility of going on the internal problems in the management level, so that the site should be disbanded, Nova does not agree Tanyasaja.com website shall be sold or auctioned off because of fears of misuse. For the active visitors Nova suggests pragmatic steps are switching to other sites since currently there are many sites that are similar to the site (Jauhari; 2010). 
Various efforts made by the management of online media to download the media in case of existence they will get a positive response to internet users who need the information to meet their basic needs as members of a community in cyberspace. The mechanism of media exposure on themselves as nettizens, was done deliberately through searching and browsing access certain sites such as; it can be found on the main stream media and social networking media such as Facebook, path, Instagram and etc.

Online media visitors or users, especially those who are concerned about health problems such as doctors, nurses or students of health disciplines, for example, has a variety of reasons on search activity on health information via the Internet. Among the principal reasons are revealed in this study is that they feel the benefits of internet access, despite the diversity of Internet users, they can take the suit benefit from wide range of information, which is turn into implications on their confidence in the ability and better health care and also the quality of medical outcomes they handle. For online media customers, the benefits of online media access in line with the magnitude of the development of online media so as to enable them to find the information they are looking for quickly and appropriately considering the development of information and knowledge about health itself is also running very quickly.

In line with the phenomenon of widespread usage of the internet site visitors online media contain health information also significant increased quantitatively and the extracted data in this study were obtained from several reasons. For example costumers are looking for health information in online media as it is designed to visitors who participate directly in matters of public health care development (public health care) or online media policy that is oriented to the health information. Growth in accessing health information from the online media directly will also reduce the burden on doctors and paramedics and even it were obliged to serve the community in the health areas, including airport information required health of consumers where the medical duty works. This will reduce the doctors and paramedics' workload, and of course the efficiency of time and the cost that must be spent consumers to obtain health information services. For consumers, there are benefits and advantages of certain health information danced through online media, namely the consumers themselves embedded attitude of independence for self-care and prevention of susceptibility of health problems. In addition, health care is done through online media to give comfort to the consumers due to the nature of the anonymity of the online media visitors on the one hand and the diversity of sources of reliable health information.

Nettizens are usually access the online health information by browsing the website through search engines. In this case, it is usually not familiar with online media that contains certain more specific information. As with the nettizens who have been regular visitors of online media, they can access health information online directly from a credible source and good source of scientific and institutional sources which are relatively justifiable from the aspects of legality and scientific aspects. Generally, from online media in general visitor (customer) will look for information about health or about issues related illnesses themselves as references before they consult a doctor or paramedic. 
Sometimes the customer is also looking for health information on behalf of others such as friends or relatives who ever happen to face and solve their health problems. The customers often access information from online media driven by the diagnosis of health problems and the desire for information about the treatment of health problems she was facing. Even from the person testimony who conducted this study, in general, the online media visitors are seeking health information as informative material pertaining to their health problems. In turn, the information found in online media are used as consideration for taking a stand and medical efforts in which the information is considered to assist them in dealing with their own health care. The more specific health information they are seeking is information relating to the problem of infectious diseases; cancers including reproductive health problems, as well as the health of mothers and children is a theme type of information often visited by nettizens.

The results of this study revealed that all informants who act as health information seekers on the online media news site, it is certain that they are part of the community in social networking although not all bounded by a community based on common interests to the search for health information. From here it was also revealed the reasons for interest in the study informants to be one member or more than one group of social communities both online and offline group. As it is the case with social communities in real communities, social groups online is also an opportunity for members to provide health care professionals; provide social support, share experiences related informative about solving the problems that are relevant to the characteristics of the group there is even a mutual effort to empower the members to meet their needs in the field of health information searches. In this study nettizen also felt the benefits of membership of an online community group that they feel like sharing information and experiences among members in many ways more useful than those consulted directly with physicians through face to face communication. Interaction and communication among members of the social community online social networking is felt more comfortable, felt more emotional support, cost effectiveness and depth of information as they expect more easily realized. In terms of the characteristics of social relations, interaction within the online community groups tend to be more egalitarian or there is equality of the role of communication between members, no partition of the partition socio-economic status, which they feel online interaction has blurred distance geographic and demographic as one of the factors that helped smooth communication in the social networking community groups so that the sense of community within the group is more easily absorbed into the soul of every member of the community.

The pattern of health information search engine in the online media, netizens conducted primarily to improve the quality of information, reached by establishing interactive communications with professional resource persons provided by online media. To increase the credibility of online media concerned the editors provide specialists who handle that consultation rubric or fill out update articles continuously. Even the most mainstream online media provide health services where 
the media visitors can consult online via machine mmessengers and consult services via e-mail. The research data is extracted from interviews with informants of this research and it reveals almost all following communication activities between online media visitors to the doctors who care for the health service rubric. However, not all the research informants claimed to actively perform activities consultative communication with their doctor because they feel by reading emails from other visitors as well as keep side by side of the doctor's informative, they find all the information already represents health problems they are facing. Nettizen are also not sure if asking a question in an online media rubric will immediately receive a response from the doctor again if similar problems are never aired and discussed in the previous period. But nettizens believe that informative questions were never sent to the online media rubric likely to be addressed by a fellow nettizens who are accessing the same information.

The access online media feel the great benefits to health information presented mainstream online media. Based on their testimony, online media is potentially rewarding (gratifications) for customers who could indicated some interesting phenomena, namely customer (Nettizen gets satisfaction on the freedom of access to health information, the satisfaction of a pattern of interactive communication between nettizens with proportional health information sources accordance with the needs of nettizens, satisfaction with the facilitation of online media to establish interactive communication and communication intentions social community network, as well as the nettizens satisfaction of the nature of the anonymity which is the collateral for the respective privacy seekers health information in the wilds of the virtual world.

Freedom in accessing to health information which is hardly limited to the virtual world is indicated by the development of online media which is easily poured relative health information and very easily accessible to visitors. Ease access is technically possible given any online media presentation of links to resources that reference, either links to other news sites as well as links to news articles that had been shown previously. The extraordinary development of the access of health information on online media as if to provide a picture almost unlimited opportunities for disseminating information, offering a learning process between patients (nettizens) with professionals resources. The interaction between nettizens as patient and professionals resource (doctors) runs in the equality of the role of the more independent and balanced communication process. Nettizen information search in the online media is freedom and comfortable without the barriers of space and time as was the case in the process of finding information on the conventional media. Participant's activity in online media communication takes place continuously in a high intensity without any time constraints. Each communication participant in online media will feel the satisfaction on the great benefits of the Internet will be its ability to interactivity, more advanced aspects of transactional rather than communication process that takes one hand linear impressed as if patronizing others, doctors patronize patients, editorial patronize visitors, dictate his audience sources and etc. Interactivity occurs as indications from many nettizens 
choice at the same time who able to join the chat (chat) that attach in the online media and we will have difficulty distinguishing which acts as a communicator which acts as a communicant. Relatively, there is no communication between the sources of the dominance of the communicant, all parties to be responsive to a characteristic that is also attached to the face to face communication.

Interactive communication about health issues in the online media opens up more opportunities for conditioning a message - a message into a variety of formats that are more individualized and more familiar with the more match communication patterns in the community. Nettizens can choose online media sites following link and the specific message he wanted based on knowledge, education or language level, according to the needs and preferences of shapes and styles, at a relatively cheap cost - how to search for information on the health of the conventional media. The nettizen satisfaction is clearly felt from the aspect of the cost and the benefits they feel in the process of finding health information in cyberspace (virtual world).

Additional value of health information searches on the online media is also felt by the NII nettizen, an online media which has the potential to facilitate interpersonal interaction and encourage the emergence of social communication network in the realm of cyberspace. Online media is always an opportunity for online media nettizens to interact with persons resources about the interpersonal health professionals such as health experts, doctors and paramedics. Furthermore, as the inherent nature of the communication behavior that behavioral changes associated with health care, the largest contribution comes from the usual pattern of interpersonal communication rather than mass communication. This means that online media can be used to promote healthy behavior change.

On the other thing from the aspect of psychological satisfaction, nettizens feel any guarantee of protection of privacy of communications activities in online media. Communication concerning issues of health information is often sensitive and related to the life of a personal nature and felt unfit to be known by others. Even if the health-related issues need to be communicated to other people in order to find the most expedient solution, the best option is through interactive communication, face-to-face interaction, and this option accommodated in online media with anonymity characteristic. Nettizens can access information about a sensitive topic; they can interact without the need to reveal the identity of each and without friendly limitation among visitors. Everyone who experience barriers in face to face communicate, can take advantage of online media as an alternative to establishing interactive communication about health issues of a personal nature.

The flood of online media message content has been categorized as a virtual overload of information in cyberspace; they spoil the access of the information by plentiful and easy. Any kind of information will easily be found even the kind of information which is not desired and access users, such as spam, advertising messages and pornography would present itself. Conversely internet sites also provide information that is valuable to the site visitors. This phenomenon that needs to be realized for any person to access information online so they can take action 
wisely in respond the overflow of information in cyberspace, from the information that is often regarded as junk (spam) until the information is worth gold. Departing from the point of view like this, it can be concluded that the internet sites can be categorized as online mass media is simply a website that meets the criteria of journalism is online mass media or online media abbreviated terms. Criteria journalism attached to online media, she also delivers online media have higher credibility than web sites in general as online media like having a clear structure's organizations and the legality of the activity of journalism under the supervision of the quality standards guaranteed, for example with the criteria of ownership ISSN or ISBN even online media that have been indexed by the highly credible international journals institution. In the end, the public or the scientific community that will assess the extent to which an online media is considered credible and able to meet the growing demands of information that can be accounted for. Instead websites that do not have credibility sooner or later be abandoned by its visitors.

Online media is a web site that has credibility in conveying the informative message, educative packaged as well as entertaining nettizen taste to meet their needs. Behind the credibility of online media, it often raises questions about the credibility of content. The credibility of the message contents are often associated with online media management agency concerned and the credibility regarding the track record (track record) personnel who handle editorial. Therefore, in general, we often see how the online media health information has races to recruit health professionals such as medical specialists as a resource for health article and build on the features of online media. Some nettizens ever accessing health information online media to benefit over the use of health information that is credible from several aspects such as the quality of information that meet the characteristics of the quality standards of health information adaptive to the target site visitors, such as; credibility, authority and trust sources that publish health information.

As the inherent philosophy in qualitative research addressing the people as individuals with different characteristics, then according nettizen quality of health information on-line media also are subjective. Each nettizen will give different assessments about the quality of health information even though the information has come from the same online media. Similarly nettizen attitude towards an informative message in which veiled messages advertising or sponsorship message. Responding to a message type or message subliminal advertising contained explicit sometimes have mixed the nettizens' view. Several nettizens feel disturbed because they feel these messages have an impact on the distortion quality of health informative messages. Parts of another nettizen understand the types of hidden ads and they are not bothered with this kind of advertising information. Another nettizens also found sponsorship message will not reduce the quality of health information content of online media throughout the online media visitors were able to sort out and be critical of the content message online media. Moreover, if the health information such as messages obviously by online media are categorized as advertorial information, it gives freedom to the access to close or 
continuous reading (if the message is packaged in a text format) the information.

Online media appointed as the object of this study is a kind of open access mainstream online media. The online media existence operation supported by financial contributions from sponsors. Therefore tracing health information broadcast by the mainstream online media comes from two sources, namely sponsorship information and a source of specific information about health. Nettizens believe that the health information from online media have credibility throughout their sources of information referring to the journal, referring to experts or academics, referring to the scientific research institutions, libraries, public institutions and professional organizations in health. Nevertheless nettizen still cannot avoid the exposure of health information found on online media in which veiled messages of advertising, but sourced from a fairly credible sources. Informative messages of this type are usually derived from online media sponsorship, consumer protection organizations or communities, and institutions - institutions volunteer health care providers.

For online media users, the credibility factor will be used as a primary consideration in accessing online information they choice. The credibility is translated as a nettizen votes or the level of their confidence in the source of health information messages, belief in the message content that reflected the views of nettizens about the extent to which health information online media are to be believed, and the extent to which the truth value of health information online media can be justified scientifically. Nettizens believe, credibility cannot be separated from the two aspects are always attached to the information published on websites that aspect of authoritativeness and trustworthiness.

The credible online media will clearly specify the identity of the author of the article and resource information. To maintain the credibility, online media sites will surely give a clear picture of who the holder of property right on a publication such as educational background, legal expertise and competence of professional organizations that houses a resource or author of the publication. The authority also includes the possibility of a problem for nettizens to verify any information from online media for the publication of websites that others such nettizen freely probably verify a health information with the public health care institutions such as hospitals, IDI, medical research institutes and so on.

Authoritativeness is also one of the indications guarantee of the credibility of information published online media with originality assurance that the information can be tracked from a primary source where online media editor provides features links to the website address so referral writings. In this way, nettizen can assess the extent to which the value of authentic of online health information from the media at the same time it can be known the extent to which authority is limited by the publication's credibility becomes the reference site.

Another element of credibility is the level of trust of the information published under the auspices of online media in the views of nettizens. The trust refers to the nettizen assessment of the character or integrity of information sources online media. This problem related to how nettizens feel the motivation of doctors and 
health experts honestly inform all relevant aspects of health care for the consequences, of course, the worst consequences that may arise if the nettizens misunderstood and incorrect in implementing the technical guidelines and informative solutions in health problems. Several things that are commonly used to assess the level of nettizen confidence sources of health information online media is the extent to which the speaker dare reveal all matters relating to health issues that were previously obscured by information from other sources that are less accountable.

Evidence of assessment nettizen on trust health information from online media websites also revealed on how nettizen assess the extent of the transparency of the online media as well as has revealed the existence of a potential conflict of interest between the alignments of the website of the sponsor who contributed greatly to the financial aspects of digital media with the demands of editors to meet nettizens needs or interests as a visitor or access of digital media information. Editors' online media are responsible and pro nettizen website visitors always will give signals to the visitor will light risks arising from media information online access. For example, online media such as Detikhealth.com always raises a warning to visitors about the content of information to be consumed only by adults. In such a warning signal, the editor of online media will give you the option to site visitors to continue access the information or leave the site. Instead nettizens will not respect the information is bombastic, message herbal, the online media such as the likelihood of the ads drugs openly promising healing instantly, drug advertising that claims to cure various kinds of diseases, product advertising multi-use but did not specify how the mechanism the products work and often does not specify the composition of the ingredients advertised. The credibility and trust from nettizen to browse health information online media will also fade when online media did not able to uncover plagiarism and referral health information presented online. Plagiarism or failure to uncover the source of the referral information will be assessed nettizen as a form of desecration of the truth values of informative media online.

Another aspect of how nettizens put his trust in sources of health information online is a refutation of the aspects related to all matters in online media with the issue; violations of the norms and ethics of online media. Feedback from online media accessed contains errors rebuttal news and misinformation that has been published by online media. Placement accuracy of information which is the corrective action of the users are online media nettizen describes how the level of trust towards online media policies. Refutation of content online media can certainly express the perspective of online media are concerned in solving it.

The tendency of the media usage behavior from time to time-shifted, individuals and people consume media is no longer on the consideration of utility and fulfillment of information but the users of mass media today almost everything is massively into the cyber space which can be said as a new space for every people interact without limitation of time and geographic location. Cyber space as a place of gathering and this diverse community also formed on the basis of interests and hobbies that unite them. They entered cyberspace with various motifs such as friendship, broaden the knowledge 
simply for entertainment, and to establish cooperation among community members over time. With the development of information and communication technology-based computers including smartphones with the Internet network as well as application programs that support it, the conventional mass media perform the metamorphosis into the cyber space that integrates with social media. Online media has become part of the digital lifestyle that cannot be separated from the culture of postindustrial society, including people of Indonesia. It is proved to the people of Indonesia is the largest market share as the participation of Internet users after the Philippines. Keep in mind that until the year 2009 in the Asia Pacific region, the number of users of internet in Indonesia by $84 \%$ while in Filipina by $87 \%$. It's can said the percentage of overall internet usage behavior, especially through access to social media such as Facebook, Twoo, Myspace, Path, Instagram, Hi5 and the like. Until 2009 social media users in Indonesia have exceeded the amount of 5074 thousand users, and the Philippines, 3924 thousands of users (Nguyen, J. 2010).

The mass media is meant portal or web sites that meet the criteria of journalism. Websites which can be categorized as mass media (online media) course web sites have certain characteristics such as publicity, universality, periodicity, continuity and timeliness (Romli; 2013).

Another consideration of the primary sources of internet users why they choose online media in particular to meet the needs of health information is considered a convenience factor, something more concerning the technical and operational aspects. Ease of use of online media is also associated with the ease to get Internet access in space - public space today. For public institutions and private institutions that are closely related to public services, the access of hotspot area, Wi-Fi router now has been regarded as an absolute form of service to the community or the vision of the institution related with the quality of service expectations of each stakeholder. Departing from the assumption mentioned above, it is now almost all public service organizations including places-public places such as airports, railway stations, bus terminals, offices and etc are already providing internet access services that significantly ease the ease of access to online media.

\section{CONCLUSIONS IMPLEMENTASION}

AND

Credibility is the criteria of the key considerations for users to access the online media in order to meet the needs of health information quickly and accurately. For users referenced resources online media is more important than just the form and content of the medium. A reference source of information by the source is often identified with a doctor or paramedic. Therefore online media that are explicitly affiliated with professional organizations such as the Indonesian Doctors Association (IDI) by nettizen perceived as a source of health information that has a high degree of credibility.

Information about health care problems by Internet users perceived as a form of urgent needs when nettizens are experiencing health problems. Similarly, if there are members of the community such as a close relative or a colleague is having a problem of health problems, then there is a strong push from nettizens to explore health information from online media. 
Online media is a source of health information effectively to meet the needs of cognition nettizens. But that obtained health information online is less effective in addressing the issue of health problems curative. For nettizen health problems that require medical treatment cannot be fully replaced with the role of online media.

The results of this research are expected to have an impact on policy implications of any health institution that provides health services to provide services that are packaged in the online media that involves health experts especially specialist. The combination of the Ministry of health via online media without leaving the service quality face to face communication between physicians and netizen is one way communication that optimize the use of technology based on the internet.

\section{REFERENCES}

Afifuddin dan Saebani, Beni Ahmad (2009). Qualitative Reseach Methods (in Indonesian Language), Pustaka Setia, Bandung.

Aldhous, P News/Feature Editor.(2001).Nature, San Fransisco, CA.

Allison S. Editor Consultant. (2000). Discovery Health and Former, Editorial direktor AOL Health, the University of Maryland, College Park, Md.

Strauss, Anselm \& Corbin, Juliet.(2003). BASIC OF QUALITATIVE RESEARCH Grounded Theory Procedures and Techniques (ed. Kamdani) , Pustaka Pelajar, Yogyakarta.

Doherty, J. Executive Producer (2000). Washingtonpost.com, Arlington, VA.

Effendi, Onong Uchjana.(1993). Science - Theory \& Communication Philosophy (in Indonesian Language), Citra Aditya Bakti, Bandung.

Eve-Marie Lcroid (2000). MEDLINEplus, Crossing the Quality Chasm: A New Health System for the 21st Century, Committee on Quality of Health Care in America, Institute of Medicine, ISBN: 0-309-51193-3, http://www.nap.edu/catalog/10027.

Griffin, Em (2006). Instructor's Manual and Test Bank to accompany: A First Look at CommunicationTheory, McGraw-Hill, an imprint of The McGraw-Hill Companies, Inc.

Harris, L.M, Diference That Make a difference, in Harris, LM. Eds.(1995). Health and News media, Technologies Transforming Personal and Public Health, Mahwah, New Jersey, Lawrance Erbaum Associates,

Hess, Thomas (2014) What is a Media Company? A Reconceptualization for the Online World. International Journal on Media Management, Volume 16, 2014 - Issue 1. https://www.tandfonline.com/doi/full/10.1080/14241277.2014.906993?scroll=top\&n eedAccess $=$ true

Miles Matthew B., Huberman A. Michael, Johnny Saldana (2014). Analisis Data Kualitatif, Buku Sumber Tentang Metode-Metode Baru, UI-Press, Jakarta, 
Jauhari,Nurudin.(2010), AlasanTanyasaja.com Ditutup, http://nurudin.jauhari.net/alasantanyasaja-com-di-tutup.jsp

McConnell, J Multi Media Editor, (2000). The Lancer, New York city, NY,

Miles Matthew B, Huberman A, Saldana Johnny (2014). Qualitative Data Analysis; A Methods Sourcebook, edition 3, SAGE Publication.

Muhadjir, Noeng, (2002). Qualitative Reseach Methods (in Indonesian Language), edition 4, Rake Sarasin, Yogyakarta,

Nejhdeh Ghevondian, Hung Nguyen, Richard John Wilshire (2010) "Patient Monitor", New Zealand Patent No. 566149 (Divisional of 543267).

Noegroho, Agoeng, (2010). Communication Technology (in Indonesian Language), Graha Ilmu, Yogyakarta.

Owens D, (1998). House A, Patchett L. Deliberate self-harm.. Effective Health Care Bulletin.

Romli, Asep Syamsul M.(2013). Komunikasi Dakwah - Pendekatan Praktis, Bandung, http://www.romeltea.com

Stepp CS, (2000).The magic and Craft of Media Writing, Chicago, NTC Publishing,

Susannah F. (2011). Health Topics $80 \%$ of internet users look for health information online, Pew Internet \& American Life Project, a project of the PewResearchCenter, Callifornia HealthCare Foundation.

Sutopo, HB, (2006). Qualitative Reseach Methods - Basic of Theory and Aplication (in Indonesian Language), Universitas Sebelas Maret Surakarta.

Tuchman, G. (1978): Making News. A Study of the Construction of Reality, New York: Free Press; Van Gorp, B (2007).

Wehrwein, P.(1997). The march of capitation: Reversed or just delayed?. Managed Care. http://www.people-press.org/2010/09/12/section-5-news-media-credibility/ 16-032016, accesed 13:43 AM. 